\title{
HUBUNGAN MOTIVASI DENGAN KEPATUHAN PELAKSANAAN DIET PADA PENDERITA DIABETES MELITUS
}

\author{
Rina Marlina Manalu,Tumpal Manurung,Yolanda Manurung \\ STIKes Arjuna Prodi D3 Keperawatan, Sumatera Utara
}

Email: manaluurina23@gmail.com; manroetumpal@gmail.com; yolandamanroe05@gmail.com

\begin{abstract}
Planning diet is a major component of the successful management of Diabetes Mellitus. The success of meal planning depends on the behavior of people with Diabetes Mellitus in choosing food include the amount of energy, the type of food, and the meal schedule. Compliance is the individual's behavior to carry out the instructions suggested by the doctor. The purpose of this study was to analyze the relationship of motivation with compliance with diabetes mellitus diet in patients with diabetes mellitus at Porsea Regional Hospital. The research design used was a cross-sectional approach. The population of Diabetes Mellitus patient at Porsea Regional Hospital was 21 respondents. The measuring instrument uses a questionnaire of motivation and compliance with diabetes mellitus diet. Data were analyzed by the Pearson Product Moment correlation test. The result of Pearson Product Moment test analysis obtained significant value 0.000 which means there is a significant relationship between the relationships of motivation with compliance diabetes mellitus diet in people with diabetes mellitus at Porsea Regional Hospital. The motivation is important because it is related to dietary changes diabetes mellitus patients are based on the patient's desire to heal and reduce the risk of complications caused by diabetes mellitus so they are motivated to follow the recommended diet program. It is expected that the nursing and doctor always motivate people with diabetes mellitus to compliance the Diabetes Mellitus diet to reduce the complications of diseases caused by Diabetes Mellitus.
\end{abstract}

Keywords: motivation, adherence, diabetes mellitus diet

\section{PENDAHULUAN}

Diabetes Mellitus (DM) merupakan suatu penyakit metabolik dengan keadaan peningkatan kadar glukosa darah (hiperglikemia) yang terjadi akibat kelainan sekresi insulin, kerja insulin atau keduanya (Berman, Snyder, \& Frandsen, 2016). World Health Organization (WHO, 2018) menjelaskan bahwa kriteria diagnosis dari diabetes mellitus (DM) yaitu apabila kadar glukosa darah puasa $>126 \mathrm{mg} / \mathrm{dl}$ atau glukosa darah acak atau random> 200 $\mathrm{mg} / \mathrm{dl}$.
Pankreas mengatur kadar gula dalam darah melalui pengeluaran glukagon, yang menambah kadar gula dalam darah dengan mempercepat tingkat pelepasan dari hati, dan meregulasi gula darah. Insulin juga merangsang hati untuk mengubah glukosa menjadi glikogen dan menyimpannya di dalam sel-selnya (Lesmana, Goenawan, \& Abdulah, 2017).

International Diabetes Federation melaporkan bahwa jumlah pasien DM di duniapada 2017 mencapai 425 juta orang dewasa dengan usia berkisar 
antara 20-79 tahun. Lebih dari 79\% pasien hidup di negara berkembang, dan diperkirakan oleh 2045 jumlah orang dengan DM akan meningkat menjadi629 juta orang. Indonesia termasuk di dalamnya 10 negara teratas dengan jumlah DM tertinggi dengan 10,3 juta orang dan diperkirakan meningkat menjadi 16,7 juta pada tahun 2045 (IDF, 2017).

Indonesia menempati peringkat keempat di dunia sebagai jumlah penderita DM terbanyak setelah India, China, dan Amerika. Kemenkes RI, (2014) melakukan penelitian di seluruh provinsi menunjukkan bahwa prevalensi toleransi glukosa terganggu (TGT) sebesar 10,25\% dan untuk DM sebesar 5,7\%. Komplikasi penyakit DM dapat mengakibatkan gagal ginjal, kecatatan, kebutaan akibat komplikasi retinopati dan 10\% harus di amputasi tungkai kaki, dan kematian sebesar 50\%. Sebaiknya dikonsultasikan dengan ahli gizi dalam perencanaan makan (diet), latihan (olah raga), pemantauan glukosa darah, dan terapi yang dapat diperoleh di pelayanan kesehatan (Puskesmas, rumah sakit, klinik dan sebagainya). Salah satu cara untuk mengurangi resiko terjadinya komplikasi dan kekambuhan dari DM adalah dengan kepatuhan penerapan diet DM (Soegondo, 2015).

Kepatuhan merupakan ketaatan atau ketidaktaatan pada perintah, aturan dan disiplin. Kepatuhan atau compliance menghasilkan perubahan perilaku yang bersifat sementara, dan individu cenderung kembali ke pandangan atau perilakunya yang semula jika pengawasan kelompok mengendur atau jika dia pindah dari kelompoknya (Sunaryo, 2013). Penelitian Yulisetyaningrum, Mardiana, dan Susanti (2018) mendapatkan ada hubungan tingkat pendidikan dan pengetahuan tentang diet DM dengan kepatuhan diet pasien.

Ahli gizi diharapkan lebih proaktif pada saat memberikan konsultasi, tidak hanya memberikan konsultasi mengenai pengaturan makan pasien DM tetapi juga memberikan motivasi pada pasien untuk terus melaksanakan diet serta mengedukasi keluarga untuk selalu mendukung jalannya pelaksanaan diet DM bagi pasien (Berman et al., 2016). Penelitian Majid, Muhasidah, dan Ruslan (2019) menyatakan adanya hubungan antara tingkat pengetahuan dengan kadar gula darah, hubungan antara sikap dengan kadar gula, dan juga hubungan antara pola makan dengan kadar gula darah. Hartanto (2016) melakukan penelitian ditemukan 53.3\% patuh dalam menjalani diet diabetes melitus.

Kepatuhan mengacu kepada situasi ketika perilaku seorang individu termotivasi dengan anjuran yang atau 
nasehat yang diusulkan oleh seorang praktisi kesehatan atau informasi yang diperoleh dari suatu sumber informasi lainnya seperti nasehat yang diberikan dalam suatu brosur promosi kesehatan melalui suatu kampanye media massa (Albery \& Munafo, 2011).

Motivasi adalah suatu dorongan dari dalam diri seseorang yang menyebabkan orang tersebut melakukan kegiatankegiatan tertentu guna mencapai suatu tujuan.Pada dasarnya motivasi merupakan interaksi seseorang dengan situasi tertentu yang dihadapinya.Oleh sebab itu motivasi adalah suatu alasan seseorang untuk bertindak dalam rangka memenuhi kebutuhan hidupnya (Notoatmodjo, 2012).

Dukungan keluarga merupakan salah satu faktor yang memiliki kontribusi sebagai faktor penguat yang mempengaruhi kepatuhan klien DM menjalani diet. Penelitian Gustina, Suratun, dan Heryati (2014) mengatakan bahwa pasien yang mendapatkan dukungan keluarga memiliki peluang untuk mematuhi diet DM sebesar 5,250 kali dibandingkan dengan pasien yang tidak mendapatkan dukungan.

Peneliti berasumsi dukungan keluarga merupakan bentuk perilaku dan sikap positif yang diberikan keluarga kepada salah satu anggota keluarga yang sakit khusus penyakit DM. Dari hasil wawancara terhadap beberapa penderita diabetes melitus, ada beberapa faktor yang mempengaruhi keluarga dalam memberikan dukungan terhadap penderita dalam menjalani diet, meliputi usia penderita, pendidikan keluarga, sosial ekonomi dan latar belakang budaya. Dengan adanya keluarga memberikan dukungan dapat mempengaruhi penderita untuk memperhatikan kepatuhan terhadap diit diabetes mellitus, sehingga kadar gula dalam darah menjadi normal dan mencegah terjadinya komplikasi.

Penelitian Gustina et al., (2014) didapatkan hubungan yang bermakna antara hubungan dukungan keluarga dan motivasi dengan kepatuhan klien DM. Penelitian Tombokan, dkk tahun 2015 didapatkan ada hubungan yang bermakna antara sikap dan motivasi dengan kepatuhan pasien DM.

RSU D Porsea, merupakan rumah sakit rujukan di Kabupaten Toba Samosir.Berdasarkan data dari rekam medik pasien rawat jalan RSU D Porsea dari tahun 2016-2018, pasien yang mendapat perawatan mengalami peningkatan. Pada tahun 2016 berjumlah 101 orang, 2017 berjumlah 146 orang, tahun 2018 berjumlah 164. Hasil wawancara pada beberapa pasien DM di RSU D Porsea bulan September 2019, dimana 6 dari 10 orang penderita DM tidak patuh dalam menjalankan dietnya, hal ini disebabkan tidak selera dengan 
menu makan yang disediakan keluarga, dan beberapa diantaranya mengatakan keluarga kurang memotivasi dalam penatalaksanaan dietnya. Berdasarkan data tersebut, maka penulis tertarik untuk meneliti hubungan motivasi dengan kepatuhan diet diabetes mellitus pada penderita diabetes mellitus.

\section{METODE}

Dalam menyelesaikan penelitian ini, peneliti menggunakan pendekatan deskriptif. Penelitian ini bertujuan untuk mengetahui hubungan motivasi dengan kepatuhan penderita DM. Penelitian dilakukan Oktober 2019. Populasi penelitian ini adalah pasien DM yang berobat ke RSU D Porsea, dengan sampel sebanyak 21 orang dengan menggunakan total sampling karena kunjungan satu bulan dapat mencapai 21 orang.

Metode pengumpulan data dilakukan dengan menggunakan kuesioner motivasi penderita DM sebanyak 17 pernyataanan kuesioner pelaksanaan kepatuhan diet DM sebanyak 23 pernyataan dengan pilihan jawaban selalu (4), sering (3), jarang (2), dan tidak pernah (1). Analisa data menggunakan uji korelasi Pearson Product Moment.

\section{HASIL DAN PEMBAHASAN}

Hasil

Data demografi responden dapat dilihat pada Tabel 1.

Tabel 1. Distribusi

Frekuensi

Responden berdasarkan

Data Demografi

\begin{tabular}{|c|c|c|c|}
\hline No & $\begin{array}{l}\text { Karakteristik } \\
\text { Responden }\end{array}$ & $\bar{f}$ & $\%$ \\
\hline \multirow[t]{5}{*}{1} & Usia & & \\
\hline & 35-45 tahun & 6 & 28,6 \\
\hline & $46-55$ tahun & 6 & 28,6 \\
\hline & $56-65$ tahun & 9 & 42,9 \\
\hline & Total & 21 & 100,0 \\
\hline \multirow[t]{4}{*}{2} & Jenis Kelamin & & \\
\hline & Laki-laki & 9 & 42,9 \\
\hline & Perempuan & 12 & 57,1 \\
\hline & Total & 21 & 100,0 \\
\hline \multirow[t]{5}{*}{3} & Pendidikan & & \\
\hline & D3 & 11 & 52,4 \\
\hline & S1 & 3 & 14,3 \\
\hline & SMA & 7 & 33,3 \\
\hline & Total & 21 & 100,0 \\
\hline \multirow[t]{5}{*}{4} & Dukungan & & \\
\hline & keluarga & & \\
\hline & $\begin{array}{l}\text { Tidak ada } \\
\text { dukungan }\end{array}$ & 2 & 9,5 \\
\hline & Ada dukungan & 19 & 90,5 \\
\hline & Total & 21 & 100,0 \\
\hline \multirow[t]{4}{*}{5} & Lama DM & & \\
\hline & $<1$ tahun & 10 & 47,6 \\
\hline & $>1$ tahun & 11 & 52,4 \\
\hline & Total & 21 & 100,0 \\
\hline
\end{tabular}

Hasil penelitian menunjukkan ratarata usia responden mayoritas 56-65 tahun (42,9\%), mayoritas berjenis kelamin perempuan $(57,1 \%)$, pendidikan mayoritas D3 (52,4\%), penderita DM mendapat dukungan dari keluarga sebanyak 19 orang $(90,5 \%)$ dan 1 orang penderita mengalami DM $>1$ tahun $(52,4 \%)$. 
Motivasi Penderita DM

Tabel 2. Distribusi Motivasi Penderita DM

\begin{tabular}{ccc}
\hline \multicolumn{1}{c}{ Motivasi } & $\boldsymbol{f}$ & $\boldsymbol{\%}$ \\
\hline Penderita & 21 & 100 \\
Motivasi tinggi & 0 & 0 \\
$\quad$ Total & 21 & 100 \\
\hline
\end{tabular}

Hasil penelitian didapatkan bahwa seluruh responden sebanyak 21 orang (100\%) memiliki motivasi tinggi dalam mematuhi diet DM.

\section{Kepatuhan Diet DM Penderita DM}

Tabel 3. Distribusi

Frekuensi

Kepatuhan Diet Penderita DM

\begin{tabular}{lcc}
\hline $\begin{array}{l}\text { Kepatuhan } \\
\text { Diet DM }\end{array}$ & $\boldsymbol{f}$ & $\%$ \\
\hline Tidak patuh & 4 & 19.1 \\
Patuh & 17 & 80.9 \\
Total & 21 & 100.0 \\
\hline \multicolumn{3}{c}{ Hasil penelitian yang dilakukan pada } \\
$21 \quad$ orang penderita $\quad$ DM & didapati \\
penderita DM & sebanyak & $17 \quad$ orang \\
(80.9\%) patuh terhadap diet DM yang \\
dianjurkan oleh tenaga kesehatan.
\end{tabular}

Tabel 4. Hubungan Motivasi dengan Kepatuhan Diet pada Penderita DM

\begin{tabular}{llcc}
\hline & & Motivasi & $\begin{array}{c}\text { Kepatuhan } \\
\text { diet DM }\end{array}$ \\
\hline Motivasi & $\begin{array}{l}\text { Pearson } \\
\text { Product } \\
\text { Moment } \\
\text { Sig. (2- }\end{array}$ & 1 & $.278^{* *}$ \\
& $\begin{array}{l} \\
\text { tailed) }\end{array}$ & & .000 \\
Kepatu- & $\begin{array}{l}\text { Pearson } \\
\text { han diet }\end{array}$ & $.278^{* *}$ & 21 \\
DM & $\begin{array}{l}\text { Product } \\
\text { Moment }\end{array}$ & & 1 \\
& $\begin{array}{l}\text { Sig. (2- } \\
\text { tailed) }\end{array}$ & .000 & \\
\cline { 2 - 4 } & $\mathrm{N}$ & 21 & \\
\hline
\end{tabular}

Hubungan motivasi dengan kepatuhan diet diabetes mellitus pada penderita diabetes mellitus di RSU D Porsea dengan hasil uji Pearson Product Moment dengan nilai $\mathrm{r}=0.278$ yang berarti ada hubungan yang signifikan antara hubungan motivasi dengan kepatuhan diet diabetes mellitus pada penderita diabetes mellitus.

\section{Pembahasan}

Hasil penelitian tentang motivasi penderita DM menunjukkan memiliki motivasi tinggi. Peneliti berasumsi motivasi tinggi pada responden disebabkan oleh karena pasien mendapat dukungan dari keluarga atau orangorang di sekitarnya dalam melaksanakan diet DM. Berdasarkan hasil wawancara kepada beberapa penderita, penderita mengatakan penderita mendapat motivasi dari keluarga, teman maupun petugas kesehatan untuk memberi semangat pasien dalam menjalani pengaturan diet.

Hasil penelitian ini menunjukkan penderita DM sebanyak mayoritas responden patuh terhadap diet DM yang dianjurkan oleh tenaga kesehatan. Penelitian Trisnadewi, Adiputra, dan Mitayanti (2018) menyatakan pengetahuan keluarga tentang manajemen DM yaitu edukasi, diet, latihan fisik dalam katagori baik, sementara pengobatan katagori 
kurang.Pengetahuan baik yang didapatkan dari informasi mengenai penyakit Diabetes Mellitus dan mengetahui cara pengaturan makan/diet yang seharusnya.

Pasien yang rutin melakukan konseling akan lebih memahami tentang penyakitnya dibandingkan dengan pasien yang tidak pernah melakukan konseling. Penjelasan tentang penyebab sakit dan bagaimana pengobatannya dapat membantu meningkatkan kepercayaan pasien untuk melakukan konsultasi untuk selanjutnya dapat membantu meningkatkan kepatuhan.

Hasil penelitian kepatuhan diet penderita DM sejalan dengan penelitian Muhasidah, Hasani, Indirawaty, dan Majid (2017) mendapatkan hubungan antara dukungan keluarga dengan motivasi dalam mengontrol kadar gula darah pada penderita diabetes melitus.Salah satu faktor risiko utama yang mempengaruhi terjadinya DM adalah pola makan yang tidak sehat dimana mereka cenderung terus menerus mengkonsumsi karbohidrat dan makanan sumber glukosa secara berlebihan, dan menaikan kadar glukosa darah sehingga perlu adanya pengaturan diet bagi pasien DM.

Penelitian Bertalina dan Purnama, (2016) terhadap pasien rawat jalan diabetes diketahui bahwa responden memiliki motivasi tinggi diketahui juga bahwa responden melakukan konseling ke Poli Gizi setelah melakukan cek kadar gula darah. Hal ini dikarenakan besarnya kepercayaan pada diri sendiri untuk menjalankan diet yang dianjurkan oleh ahli gizi dengan menjaga pola makan ditambah dengan mengonsumsi obat-obatan yang diresepkan oleh petugas kesehatan.

Berdasarkan analisa data pada 21 orang penderita DM didapati bahwa rata-rata penderita DM sebanyak 17 orang $(80,9 \%)$ patuh terhadap diet DM yang dianjurkan oleh tenaga pelayanan kesehatan. Hal ini menunjukkan bahwa penderita DM patuh terhadap diet DM yang dianjurkan. Kepatuhan merupakan suatu perilaku manusia yang taat terhadap peraturan, perintah, prosedur dan disiplin. Kepatuhan tertuju terhadap instruksi atau petunjuk yang diberikan dalam bentuk terapi apapun yang ditentukan, baik diet, latihan, pengobatan. Keyakinan, sikap dan kepribadian juga sangat berpengaruh kepada kepatuhan pasien dalam pelaksanaan diet karena faktor tersebut adalah faktor internal dalam diri seseorang. Orang yang memiliki kepribadian yang pesimis akan mudah menyerah dalam menghadapi pengobatan serta pengaturan makan karena merasa bahwa pengobatan tersebut sangat sulit dilakukan. 
Hal ini sejalan dengan pendapat Berman et al. (2016), yang mengatakan motivasi klien untuk sembuh akan mempengaruhi perilaku dan akan melakukan perubahan gaya hidup sehingga terapi yang diprogramkan akan terlaksana dengan baik.

\section{Hubungan motivasi dengan kepatuhan diet pada penderita diabetes mellitus}

Hasil penelitian ini didapati ada hubungan yang signifikan antara hubungan motivasi dengan kepatuhan diet pada penderita diabetes mellitus. Semakin baik motivasi pasien maka tingkat kepatuhan diet semakin tinggi.Sebaliknya, semakin rendah motivasi pasien maka tingkat kepatuhan diet semakin rendah.

Hasil wawancara yang dilakukan, responden dengan motivasi yang tinggi serta patuh terhadap diet menyatakan bahwa mereka percaya bahwa dengan menjalani diet tubuh mereka akan merasa lebih baik karena gula darah terus terkontrol. Hal ini berkaitan dengan pengetahuan mereka tentang diet DM yang baik serta mendapat dorongan motivasi dari keluarga dan petugas kesehatan untuk mematuhi diet.Pemberian informasi yang mendalam tentang DMsangat penting untuk dilakukan agar tingkat kepatuhan diet pada pasien meningkat dan menurunkan terjadinya risiko keparahan penyakit dan komplikasi serta dapat mengontrol gula darah pada pasien.

Akan tetapi hasil penelitian ini tidak sejalan dengan penelitian Kusnanto, Susanti, Ni'mah, dan Zulkarnain (2019) dimana menunjukkan tidak ada korelasi antara motivasi dan kepatuhan diet, dan adakorelasi antara locus of control kesehatan dengan kepatuhan diet.

Hasil penelitian ini sejalan dengan penelitian Purwandari dan Susanti, (2017) ada hubungan antara kepatuhan diet dengan kualitas hidup penderita diabetes mellitus dalam kategori cukup. Kepatuhan diet, pola makan, istirahat, dan olahraga yang dilakukan secara seimbang dapat mengatur kadar gula dalam nilai normal yang memberikan kesehatan pada penderita.

Dukungan keluarga dalam bentuk dukungan emosional dari anggota keluarga yang lain merupakan faktor yang penting dalam kepatuhan terhadap program diit yang dijalankan dengan adanya dukungan akan membuat penderita yakin patuh dalam melakukan diit (Sunaryo, 2013). Penelitian D'Souza et al. (2017) menunjukkan kepatuhan orang dewasa membuat mereka mengambil keputusan dengan meningkatkan self-efficacydengan mematuhi diet DMuntuk meningkatkan derajat kesehatan. Pelaksanaan diet sangat dipengaruhi oleh adanya dukungan keluarga pasien. 


\section{KESIMPULAN DAN SARAN}

Hasil penelitian menunjukkan seluruh responden memiliki motivasi tinggi dalam mematuhi diet, sebanyak 17 orang (80.9\%) patuh terhadap diet DM yang dianjurkan oleh tenaga pelayanan kesehatan. Hasil analisa uji Pearson Product Moment nilai signifikan 0,000 yang berarti ada hubungan antara motivasi dengan kepatuhan diet diabetes mellitus pada penderita diabetes mellitus.

\section{Saran}

Diharapkan kepada pihak pelayanan keperawatan agar selalu memotivasi penderita diabetes mellitus untuk patuh terhadap diet DM sehingga mengurangi terjadi komplikasi penyakit dan diharapkan kepada keluarga agar selalumemotivasi penderita untuk patuh terhadap diet, dan sebagai keluarga dapat mengontrol makanan sehingga tidak menjadi penderita DM pada masa yang akan datang.

\section{DAFTAR PUSTAKA}

Albery, I. P., \& Munafo, M. (2011). Psikologi kesehatan panduan lengkap dan komprehensif bagi studi psikologi kesehatan. Jakarta: Palmall.

Berman, A. T., Snyder, S., \& Frandsen, G. (2016). Kozier \& Erb's fundamental of nursing. In Pearson.

Bertalina, B., \& Purnama, P. (2016). Hubungan lama sakit, pengetahuan, motivasi pasien dan dukungan keluarga dengan kepatuhan diet pasien diabetes mellitus. Jurnal Kesehatan. https://doi.org/10.26630/jk.v7i2.211
D’Souza, M. S., Karkada, S. N., Parahoo, K., Venkatesaperumal, R., Achora, S., \& Cayaban, A. R. R. (2017). Self-efficacy and self-care behaviours among adults with type 2 diabetes. Applied Nursing Research. https://doi.org/10.1016/j.apnr.2017.0 5.004

Gustina, Suratun, \& Heryati. (2014). Faktor-faktor yang berhubungan dengan kepatuhan diet diabetes mellitus pada pasien DM. JKep, 3(2), 97-107.

Hartanto Dedy; Utoyo Bambang; Putra Agina W.S. (2016). Hubungan kepatuhan diet dengan kualitas hidup pada penderita diabetes melitus di RS PKU Muhammadiyah Gombong. Kesehatan. https://doi.org/10.5151/cidi2017-060

IDF. (2017). IDF Diabetes Atlas 8th Edition 2017 Country Reports Kenya | Report Builder. International Diabetes Federation.

Kemenkes RI, P. D. dan I. (2014). Infodatin: Waspada Diabetes. Decision Support Systems. https://doi.org/10.1016/j.dss.2003.08. 004

Kusnanto, K., Susanti, R. D., Ni'mah, L., \& Zulkarnain, H. (2019). The correlation between motivation and health locus of control with adherence dietary of diabetes mellitus. Jurnal Ners. https://doi.org/10.20473/jn.v13i2.970 0

Lesmana, R., Goenawan, H., \& Abdulah, R. (2017). Fisiologi dasar untuk mahasiswa farmasi, keperawatan dan kebidanan. Yogyakarta: Deepublish.

Majid, N., Muhasidah, M., \& Ruslan, H. (2019). Hubungan tingkat pengetahuan, sikap dan pola makan dengan kadar gula darah pada penderita diabetes mellitus di Wilayah Kerja Puskesmas Sudiang Kota Makassar. Media Keperawatan: Politeknik Kesehatan Makassar. https://doi.org/10.32382/jmk.v8i2.45 3 
Muhasidah, Hasani, R., Indirawaty, \& Majid, N. W. (2017). Hubungan dukungan keluarga dengan motivasi dalam mengontrol kadar gula darah pada penderita diabetes melitus di wilayah kerja Puskesmas Pampang Kecamatan Panakkukang Kota Makasar.

Notoatmodjo, S. (2012). Promosi Kesehatan \& Ilmu Perilaku. In Jakarta: Rineka Cipta.

Purwandari, H., \& Susanti, S. N. (2017). Hubungan kepatuhan diet dengan kualitas hidup pada penderita $\mathrm{dm}$ di poli penyakit dalam RSUD kertosono. Strada Jurnal Ilmiah Kesehatan. https://doi.org/10.30994/sjik.v6i2.3

Soegondo, S. (2015). Penatalaksanaan diabetes melitus terpadu. Jakarta: Balai Penerbit FKUI:2014. In : FKUI.

https://doi.org/10.1002/cjce.20502

Sunaryo. (2013). Psikologi untuk keperawatan. Jakarta: EGC.

Trisnadewi, N. W., Adiputra, I. M. S., \& Mitayanti, N. K. (2018). Hubungan tingkat pengetahuan diet diabetes mellitus dengan kepatuhan diet pada penderita diabetes mellitus tipe II di dusun Karang Tengah Yogyakarta. Bali Medika Jurnal. https://doi.org/10.36376/bmj.v5i2.33

WHO. (2018). Diabetes Programme. World Health Organization.

Yulisetyaningrum, Mardiana, S. S., \& Susanti, D. (2018). Hubungan tingkat pendidikan dan pengetahuan tentang diet DM dengan kepatuhan diet pasien diabetes mellitus di RSUD R.A Kartini Jepara. Indonesia Jurnal Perawat. 